\title{
Practices of solidarity in the COVID-19 pandemic
}

\author{
Stefanie Börner (stefanie.boerner@ovgu.de) \\ Otto-von-Guericke-Universität Magdeburg, Germany
}

Insights from research on previous crises and studies that compare different crises suggest that each crisis creates its own version of solidarity or de-solidarization (Agustín \& Jørgensen, 2016; della Porta, 2018; Lahusen \& Grasso, 2018). Viewed together, the papers of this special issue provide examples of the manifold facets of solidarity and offer an initial overview of how COVID-19 has altered the existing solidarity landscape in Europe during the first half of 2020 when the first wave reached most European states. They contribute to a broad understanding of solidarity as a continuum of practices that take place between the private and the public sphere, with individual volunteers (as well as civil-society organizations) and different public actors constituting the two poles of this continuum. This introductory paper discusses the various support efforts that suggest an augmented sense of solidarity. First, the topic of this special issue is embedded in the research on solidarity and crisis, before the key results of the individual contributions are summarized and discussed. Organized along the analytical distinction between civic (2.1) and public solidarity (2.2), the overview then provides an explanation of the observed pandemic-related solidarities (2.3). In discussing the future implications and long-term perspective of the surge in solidarity that we are witnessing right now the final section also raises the question as to whether there will be signs of de-solidarization in the long term.

Keywords: Civil society, crisis, disaster, solidarity, welfare state

\section{Solidarity in times of crisis}

Crises are "both a threat to and an opportunity for solidarity" (Koos, 2019, 629). The COVID-19 pandemic, which has been framed as a major crisis and often even a disaster in the media and by governments all over the world, made this more than clear. While the pandemic abruptly disrupted existing patterns of solidarity, it spawned an impressive spectrum of new practices of solidarity, both from below, by individual volunteers and civilsociety organizations, and from above, in the form of policies directed towards supporting specific groups. If we probe deeper into these empirical observations, the processes to which they point raise more fundamental questions with respect to the relationship between solidarity and crises. Questions such as, what is the relationship between state and private or civil-society solidarity and how do the new practices relate to the ones we consider as traditional-or taken-for-granted-practices of solidarity? How can we explain these emerging practices? Do pandemic-related practices of solidarity differ from the solidarity practices of other crises? And last but not least, what remains once the crisis is over? Are the crisis-induced practices and policies likely to alter the previously existing solidarities? These are some of the questions the papers in this special issue tackle. 
Triggered by a succession of crises in Europe, research on crises-induced solidarity has flourished during the last two decades (Lahusen \& Grasso, 2018; Gerhards et al., 2019). Crises, Koos $(2019,631)$ argues, are "a necessary, but no sufficient conditions for solidarity". Between 2009 and 2012, the European debt crisis was said to have triggered a process of de-solidarization in Europe, particularly in terms of transnational solidarity, because the crisis harmed trust and the transnational processes that connect people (Polyakova \& Neil Fligstein, 2016).

"[T]hose countries particularly affected by the crisis (e.g., Greece) perceive the intraEuropean wealth distribution as unjust, and less affected countries such as Germany as "arrogant" and "lacking compassion". In turn, many Germans perceive Greece or Italy as the least trustworthy and hardworking EU countries." (Reese \& Lauenstein, 2014, 161)

Starting in the summer of 2015, the EU's refugee reception crisis, by contrast, turned into a crisis of international solidarity in Europe since it revealed the reluctance of individual member states to take responsibility and their lack of commitment to a common EU migration and asylum policy (Wallaschek, 2020). At the same time, the experiences and the virtual collapse of the members states' public infrastructure to receive and integrate refugees unleashed a wave of civic solidarity. According to a study by Lahusen and Grasso $(2018,262)$, "almost every third respondent had been engaged in practices of support for migrants". This massive mobilization contributed to the development "of new forms of everyday politics and acts of solidarity" (Agustín \& Jørgensen, 2016, 3):

"In Austria 2,200 drivers joined a campaign to pick up refugees stranded in Budapest. In Germany, Denmark and Sweden, locals have organized support for arriving refugees, donating food, water, clothes and other supplies to those in need, sometimes using civil disobedience by smuggling refugees to neighbouring countries or sheltering refugees privately. In Iceland, more than 11,000 Icelanders (out of a total population of approximately 323,000 people) offered to accommodate Syrian refuges in their private homes and pay their costs as a response to the government suggesting that it would accept 50 Syrian refugees." (ibid., 3)

In contrast to these disruptive "acts of resistance" (della Porta, 2018, 4), the practices observed in the context of the pandemic are more fundamental in nature. They seek to compensate for a partially failing public infrastructure and provide for the recipients' most basic needs in a situation marked by a general shutdown or even paralysis in many areas of social life.

With an eye to the particular nature of the COVID-19 crisis, the research compiled in this special issue makes three assumptions. The first assumption is that this crisis differs considerably from other crises that are less universal and do not encompass all areas of life. Civic and political crisis reactions differ strongly depending on the origin of the crisis, the societal effects and the political climate. The current pandemic crisis differs in several respects from the debt crisis and the refugee reception crisis mentioned above. Although all of these crises were global in scope, only COVID-19 has made its effects felt on everyone, albeit to varying degrees. A further unique feature of the pandemic-induced crisis is that it leaves less room to blame others than previous crises and that there thus is - at least at first glance and during this very first wave that this issue addresses-much more room for unconditional solidarity than in other critical situations. For instance, think of the European Stability Mechanism (ESM) introduced in 2012, which made support via bailout loans conditional upon member states implementing austerity programmes to promote their fiscal consolidation. What is more, compared to other crises, COVID-19 created new alignments of in- and outgroups and thus a seemingly broader or even universal basis for solidarity (see below). The lines of conflict that have emerged as a consequence of the political and 
social dynamics unleashed by the virus (e.g., between a mainstream complying with the rules and a deviant minority, or between the advocates and the opponents of vaccination) diverge even more from the ones that define the traditional political camps.

The special issue's second assumption is that civil-society solidarity, particularly during a crisis, brings to light pronounced weaknesses within traditional spaces of institutionalized or public solidarity. Thus, COVID-19 solidarity is not only a reaction to decades of cutbacks in public spending in welfare-state retrenchment but also a response to a lack of epidemic knowledge, crisis-management plans and a reliable supply of medical products and protective equipment. Even though Europe had faced previous epidemics such as SARS, swine flu or bird flu, think tanks and international organizations like the WHO and Bertelsmann saw many European states as having been poorly prepared for a pandemic such as the one caused by COVID-19 (Schiller \& Hellmann, 2021; WHO, 2020).

The third assumption pertains to the different spatial levels at which the various practices of solidarity play out. When the virus first reached Europe in January 2020 and national lockdown regulations were implemented in most European states, the dominant perspective underpinning such action was one that involved a re-nationalization process (Rachman, 2020). The articles in this volume assume that it is not sufficient to study the crisis and the responses to it as national phenomena. Hence, the special issue aims at studying the manifold versions and practices of solidarity emanating from the pandemic and the political responses to it in Europe. The studies enquire into the local experiences and practices of solidarity across borders, compare different responses to the pandemic in different countries, or study the dynamics of transnational solidarity in Europe in the wake of COVID-19. The scope of solidarity practices studied thus ranges between local, national, transnational and international solidarity. The studies enquire into the local experiences and practices of solidarity, compare different responses to the pandemic in different countries, or study the dynamics of transnational solidarity in Europe in the wake of COVID-19. This implies that solidarity is used in a wide sense here, comprising different facets of solidarity such as humanitarian, mutual, religious, activist or political.

From an analytical perspective, the scholars in this issue study solidarity from three different angles: the meso level of institutionalized solidarity, the macro level of aggregate public sentiment in matters of solidarity, and the political discourse on solidarity. First, at the meso level solidarity emerges as collectively organized practices that strive to support others. Depending on the actors, these can either materialize as private or rather civic solidarity 'from below' or as state or EU-level solidarity from above, which is often referred to as institutionalized solidarity (Gelissen, 2000). The latter takes the shape of public institutions that intend to guide citizens' behaviour or as policy measures that intervene in and seek to direct and control the often most private human affairs.

Second, besides directly studying these practices of solidarity, we can also investigate solidarity indirectly at the aggregate macro level in terms of individual preparedness to support others or the acceptance of public solidarity. Although this study of attitudes towards solidarity does not replace information on direct practices and activities, attitudes do provide a useful measure to assess the overall atmosphere and public sentiment.

The third perspective applied here is the study of solidarity discourses. Similar to the second approach, examining political discourses provides an indirect measure of solidarity. Especially as a political concept and discursive practice, solidarity is subject to strategic use. It more often than not refers to a lack of solidarity or appeals to the necessity to act in solidarity than to the practices themselves. Insights on how public authorities or the media frame specific subjects and how solidarity is semantically and strategically used in the political arena complete the complex picture of today's solidarity practices.

Each of the perspectives comes with its own strengths and weaknesses, yet altogether they lay out a panorama of how COVID-19 has affected the practices of solidarity and the 
way European societies have reacted to the pandemic. These practices differ in scope and their degree of commitment. For instance, civic solidarity often has a local scope but is marked by a tremendous commitment.

In the following, I will summarize and discuss the key results of the individual contributions. This presentation is guided by the analytical distinction between civic (2.1) and state solidarity (2.2) introduced above and closes with an explanation of the observed pandemicrelated solidarities (2.3). The final section discusses the future implications and long-term prospects of the surge in solidarity that we are currently witnessing (3).

\section{Outlining the major insights of this special issue}

\subsection{Solidarity from below}

COVID-19 has raised the question of solidarity in an unprecedented manner because the pandemic has touched upon the existing care arrangements within society and the division of labour between public agencies, civil-society organizations, families and workplaces. This is why several of the analyses in this issue discuss the relationship between two fundamental types of solidarity when approaching solidarity analytically from the side of those enacting it, that is, (public) state or top-down solidarity on the one hand and private bottom-up practices of solidarity such as the ones enacted by civil-society organizations or volunteers on the other.

Between February and May 20202 all over Europe, a dense network of solidarity practices has emerged that comprises both existing civil-society organizations and spontaneous initiatives by volunteers who organize mask-sewing groups or offer neighbourhood assistance for high-risk groups or people in need. Three case studies on local practices of solidarity during the first wave of infections provide major insight into how existing civil-society organizations reacted not only to the first COVID-19 wave but also to the challenges linked to the pandemic such as the inability to pursue established forms of exchange and support, the impossibility of reaching the target groups and thus the need to invent or try new practices and communication channels.

In their study on local care networks in Madrid, Andrés Walliser Martínez and François De Gasperi show how COVID-19 has mobilized a wave of solidarity that focused on the provision of care at the neighbourhood level. Since early March 2020, informal and horizontal care networks - some of which were new, some of which originated in Spain's associative tradition and the 15-M anti-austerity movement-have provided food to thousands of people in several neighbourhoods of the Spanish capital on a weekly basis. The paper examines how civil society provided care through social innovation and long-established forms of urban activism and analyzes how care is conceptualized in relation to the Spanish family-centred welfare state in a context of crisis. The authors shed light on the role of participative local policies and community action in providing care during the current COVID-19 crisis. They then show that some aspects of care have reignited the idea of the commons in order to respond to a neoliberal city in crisis and assess the political emphasis on the 'City of Care' strategy developed by the previous New Municipalist local government between 2015 and 2019. From a social-movement perspective, the paper underscores the importance of existing networks, which enabled care networks to reactivate and organize assistance extremely quickly in spring 2020 because of their ability to draw on established structures.

Micha Fiedelschuster and Leon Rosa Reichle analyze the varied forms of neighbourly support groups during the pandemic in Leipzig, Germany. In their interview study, they reconstruct the trajectories of six different groups between May and September 2020 and highlight different organizational approaches, understandings of solidarity, normative horizons, transformative aspirations and practical barriers to these aspirations. The authors 
analytically classify the groups by applying three different sociological conceptions of solidarity (solidarity based on shared identity, as a moral duty or as a transformative political practice) and highlight their blurry boundaries in practice. The study points to the different motives for solidarity on the ground and the transformative potential of the groups' activism before reflecting on it in relation to their socio-spatial locations within the city.

Drawing on ethnographic fieldwork, Alessandro Mazzola and Mattias De Backer's case study on solidarity towards vulnerable migrants in Brussels compares the 2015 refugee reception crisis with the pandemic. COVID-19 has not only brought about a shift in political priorities and pushed refugee issues to the margins. It has also entailed measures to contain the pandemic some of which have had a strong impact on migration (e.g., closing of borders, halt to asylum applications). At the same time, the civil-society support to migrants that had emerged in response to the long summer of migration in 2015 was almost completely stopped. This revealed even more clearly that authorities were ill-prepared for-or not concerned at all with-protecting vulnerable groups such as refugees, asylumseekers and undocumented migrants from the pandemic. The initiatives studied operated in an improvised, creative and hybrid fashion, sometimes stretching their original mission. These forms of solidarity bring to light the pronounced weaknesses within the traditional spaces of state solidarity and the reality that the two crises have overlapped rather than one following the other. The pandemic further intensified the problems associated with the reception crisis.

The first wave of the COVID-19 pandemic and the political responses to it also gave rise to a multitude of new local initiatives. Some of these initiatives operated online only, others led to the formation of small organizations or networks; some maintained good contacts to local government, others remained purely private; and some provided monetary help, while others supplied all kinds of support, starting from shopping services for groups at risk and operating an emergency hotline up to the collection and distribution of food and clothes or the organization of meeting points for people without shelter.

One of these new solidarity practices that was typical of the first wave of the pandemic was the formation of mask-sewing groups and the local organization and distribution of face masks, which Janine Kuhnt examines in her study. Conducting an online ethnography and applying a network-analytical perspective to self-presentations of community foundations, she deals with the question of how these grassroots organize the production and provision of masks. Kuhnt shows how volunteers helped to meet the local demand for face masks by both mobilizing the necessary resources and producing masks. In producing a scarce product, the voluntary and solidarity-based engagement becomes market-relevant. At the same time, the author concludes that solidarity is a fragile basis for action because it arises from the active engagement of citizens, which also rests on expectations of reciprocity.

Face masks are also exemplary of the short-lived nature of some solidarity practices during the pandemic. While they constituted one of the first issues seized by local initiatives and active citizens, the supply of handmade cloth masks has disappeared from the agenda since the end of second wave because some European states (for instance, Italy, France, Germany and the Czech Republic) have adopted measures requiring medical face masks. As a consequence, this partly shifted the practices of solidarity from the private to the public level as public authorities now began to ensure that everyone had access to these more expensive kinds of face masks.

While the political measures adopted to contain COVID-19 produced a new wave of spontaneous solidarity that benefited the elderly, now labelled at-risk-group, and to a lesser degree those in (temporary) financial difficulties, they also disrupted existing solidarity structures for those who were in need before and whose neediness had even been aggravated given the lockdown and social-distancing measures. Thus, the studies at hand draw 
a broad picture of how the pandemic not only has unleashed citizens' initiatives and voluntary engagement but also has affected existing practices of solidarity from below that often had to shift their original mission because the virus had complicated the work of established groups.

The articles' insights that the crises responses from below are creative and hybrid solutions are not new to the field of civil-society studies of course, yet they help to frame and advance existing insights. I want to point out three aspects specifically: the intertwining of different crises, the hybridization of actors and the state-civil society relationship. First of all, the case studies allow different crises to be compared and connected in a fruitful way. With the outbreak of the pandemic, different crises began to intersect in many ways. This becomes most obvious with respect to specific groups that had already been marginalized before, such as asylum seekers, homeless people, food-bank clients or residents of social shelters. The activities studied in this issue all have in common that they address issues, resources or social groups that have been neglected by the government responses, but they also shed light on previously existing social discrimination and inequalities that COVID-19 has only rendered more visible and precarious. As for the refugee reception crisis starting in 2015, Mazzola and De Backer conclude, as pointed out above, that the spontaneous forms of solidarity reveal weaknesses in the traditional forms of providing state solidarity. Yet the current pandemic not only overlaps with the refugee reception crisis but also with the financial crisis of 2008 or, even more general, with the crisis of the welfare state in the 1990s, which suggests that these crises tell us something about the deficits of national and EU social policies and the suboptimal outcomes that have resulted from many years of privatization, labour-market deregulation, austerity and spending cuts in the health and social-service sectors. Hence, there is more continuity between these crises than most observers would expect, given that the scale and consequences of a crisis as well as how these consequences are distributed over the population result from decisions that were taken in the past (before the latest crisis or during previous crises). When COVID19 produces "a crisis on top of a normalized crisis" (see Mazzola \& De Backer, 2021, in this issue), this raises the question of when exactly crises end, even if the media and politicians have framed previous crises as having been overcome.

Second, the creative practices of exercising solidarity range from improvised help via temporary digital channels such as social media platforms and videotelephony, through reinterpreting an organization's original mission or the temporary rededication of hotels, museums and so on to the creation of new private-public networks to manage the distribution of face masks or food. Many of these citizens' initiatives are hybrid in the sense that they include a great variety of actors (artists and cultural workers, social workers, activists, civil servants and volunteers) and mobilize extremely different resources. In many cities, these informal and spontaneous practices seemed to have influenced the local governance of the crisis to a considerable degree (Walliser \& De Gasperi, 2021).

Third, in view of classical third-sector research (Salamon, 1995; Young, 2000), the pandemic-driven practices of solidarity can be characterized as complementary and supplementary instead of adversarial. Broadly speaking, they address the gaps left by the state and thereby-as some would argue-implicitly endorse public policies and bolster the political system. Although the fact that most of those who engage in these solidarity practices do not explicitly criticize the role of the state does not mean that they agree with the measures adopted, their practices of support indeed leave little room for more subversive or activist initiatives. Some of the groups studied that were already active before the outbreak of the pandemic even broadened the scope of their activities beyond their initial more political mission (see Mazzola \& De Backer, 2021 and Fiedlschuster \& Reichle, 2021, both in this issue). While voluntary activities during the financial crisis often appealed to concepts such as the solidarity economy (Rakopoulos, 2014) and activists driven by 
humanitarian concerns during the 'summer of migration' also endorsed illegal practices, today's volunteers and grassroot activists operate in a totally different crisis environment where the boundaries between legal and illegal practices and between supporters and those supported have shifted towards a more harmonious state-civil society relationship. Even so, the case studies show that civil-society organizations are as non-linear and dynamic as the crises to which they are reacting, which renders such organizations much more agile than a state agency or local administrative body.

\subsection{The politics of solidarity: Solidarity from above}

All of the papers discussed above present their arguments against the backdrop of another type of solidarity, namely, institutionalized or state solidarity. Most social scientists agree that during the second half of the twentieth century modern welfare states institutionalized the solidarities that define the societal relationships between different social groups and thus replaced some of the traditional (church, neighbourhood or private) solidarities that prevailed during the nineteenth century (Gelissen, 2000; Börner, 2013). However, during the last few decades, social-policy makers tended to emphasize fiscal stability, cost containment and market conformity. In sharp contrast to these reform paths, from the moment of its outbreak COVID-19 posed the question of welfare-state solidarity anew. As a health crisis, it first and foremost directly affected healthcare systems, starting from patient care to the procurement of medical devices, protective equipment and vaccines. Second, the so-called lockdown that was implemented all over Europe with the exception of Sweden made further crises responses by national governments necessary, such as the temporary expansion or relaxation of eligibility rules, provisional increases of some benefits, suspension of conditionality, the introduction or expansion of short-time work schemes or the issuance of one-off payments such as the German child bonus to name but a few. The policies were tailored towards stimulating the economy and getting people back to work, yet the groups that they addressed differed from country to country. Last but not least, the pandemic-induced crisis has exacerbated social inequalities along the prevailing lines of conflict and has deepened existing labour-market divisions or healthcare deficits. Several studies show that the COVID-19 crisis has hit the most vulnerable hardest. For instance, low-wage employees in Britain (who often coincide with the new category of socalled 'key workers') face the most pandemic-related health and social risks because they do not work at home, are over-represented in temporary and part-time work and most at risk of unemployment and social deprivation (Gustafsson \& McCurdy, 2020, 14-16). Against this background, some scholars argue that while the first wave saw a heyday of civic solidarity, "the importance of institutional solidarity is receiving more prominence" due to the continuing crisis (Prainsack, 2020, 127).

"Amid all the talk and excitement around learning healthcare systems and resilient societies in recent years and decades, what the COVID-19 crisis has taught us so far is that the most resilient societies are not those that have the best technologies or most obedient citizens. It is those that have solidaristic institutions." (ibid., 130)

This renders the pandemic in several respects the hour of welfare states since they are the major social-policy providers. In this issue, Olivier Giraud, Tanja Toffanin, Nikola Tietze and Camille Noûs zero in on three public-health systems-France, Germany and Italy-and compare their crises management. The three healthcare systems represent complex and differentiated institutional arrangements that have undergone far-reaching reforms, mostly of liberalization, during the last four decades. In particular, their funding and resources have been subject to incisive transformations and sometimes drastic cutbacks, which is why the authors point to the discrepancy between the appeal to national solidarity and the long-institutionalized policy agenda of containing public spending in the 
domains of health and social policies. The authors provide a brief institutional-comparative analysis of the French, German, and Italian healthcare systems and analyze the conceptions of solidarity implicit in the policy discourses and the legal measures at the moment of the first lockdowns. In a second step, their analysis focusses on two key operational measures in the fight against the pandemic: testing strategies and availability of intensive care beds, both of which require the implementation of a specific conception of solidarity as well as the coordination of different actors and policy levels. The three countries, the authors argue, have all undergone a phase of centralization of the decision-making process in the context of the COVID-19 pandemic. The health systems' governance patterns and their funding logics have influenced greatly the provision of both tests and intensive care beds. The crisis has shed light on the shortages of nursing staff and the effects of economization of work relations in the hospital system. In Italy, for instance, the insufficient intensive care unit bed capacities have been an obvious consequence of the economization of healthcare in Italy, due to austerity measures in this sector. Overall, the comparison of the French, German and Italian cases reveals tensions and conflicts linked to the distribution of resources and power between the various levels of governance which shed light on their respective path to marketization and individualization of responsibility.

Assuming that solidarity is relevant at not only the policy but also the discursive level as a crucial element of the political rhetoric, Stefan Wallaschek and Franziska Ziegler address the crisis-solidarity relation by examining how heads of government communicated to the public during the COVID-19 pandemic. Their paper assesses to what extent and in which way solidarity featured in public speeches in Ireland and New Zealand. Their analysis builds on the assumption that the political orientation of actors shapes the framing of solidarity. It emphasizes different forms of solidarity and studies the policy fields the heads of government address as well as the scope of their solidarity claims (national versus international). Wallaschek and Ziegler conduct a qualitative content analysis of the public communication of Leo Varadkar and Jacinda Ardern, the prime ministers of the two countries, between late February and June 2020. The analysis shows that the concept of solidarity is omnipresent in both leaders' rhetoric despite their different political orientations. This sheds light on the specific crisis constellation that differs considerably from previous crises that triggered other, more conditional forms of solidarity. Much like the crisis itself, the kind of solidarity that the two heads of state refer to when addressing their audiences is rather universal. Their speeches document how solidarity works not only as a legitimizing concept but also a concept that links different domains in a complex crisis, in this case public health and economic development specifically. Their frequent evocation of solidarity not only addresses their governments' own activities and policies, which they generously frame in terms of exercising solidarity, but also appeals to the citizens' responsibilities during such a health crisis, which for them is, for instance, to comply with the rules such as wearing masks and maintaining social distance. Ardern's framing of the crisis as a collective task of all New Zealanders to unite and rebuild public health and the economy is an interesting case of official solidarity rhetoric, for she presents solidarity not only as a sovereign task but as collective endeavour. This clearly has the signature of New Zealand's neoliberal footing. With a view to the other studies in this issue, the frequent appeals to individual responsibility, mutual support and burden sharing that are also present in government speeches in Europe provides the soundtrack to the practices of solidarity from below, and one could speculate that these have worked as a mobilizing force. Furthermore, with respect to the scope of publicly proclaimed solidarity, the authors show that national leaders frame their claims and appeals as domestic issues as they speak on the national stage to their respective citizenry.

In addition to national policies and communication, the pandemic obviously has a panEuropean and global dimension. With respect to transnational solidarity from above 
during COVID-19, German sociologist Jürgen Gerhards (2020) distinguishes two versions: one is supranational or bilateral solidarity directly related to public health and medical care of COVID-19 patients such as cross-border treatment of intensive care patients and the distribution of protective equipment, medicines or-more recently-vaccines; the other is EU policies that aim at managing the social and economic consequences of the pandemic. Starting from previous findings that there is popular support for these kinds of transnational solidarity at the EU level, Zsófia S. Ignácz and Alexander Langenkamp explore the underlying structure of European solidarity in order to figure out whether COVID-19 might be a new catalyst for European solidarity. Using a primary dataset collected in Germany between 27 March and 26 April 2020, the paper investigates individual willingness to extend solidarity transnationally. With the help of confirmatory factor analysis, the authors examine how attitudinal questions about support for European citizens and healthcare institutions under the COVID-19 pandemic relate to other forms of European solidarity, that is, fiscal solidarity and welfare-state solidarity. If solidarity related to the COVID-19 pandemic can be clearly distinguished from other forms of solidarity, Ignácz and Langenkamp argue, then the catalyst for solidarity plays a decisive role in structuring European solidarity. However, if European solidarity is structured along the type of recipient (individual or state actor) or by the motive that guides solidarity, such as risk sharing or redistribution, COVID-19 solidarity does not constitute a new form of transnational solidarity in Europe. The analysis shows that European solidarity in the context of COVID-19 is not a distinct form of European solidarity. Rather, what seems to guide the respondents' support for transnational solidarity in Europe is whether this solidarity addresses individuals or other states. This means that people distinguish between who benefits from the respective supranational practices of solidarity: a member-state government, the sick, the elderly and so on. Hence, the theoretical construct of European solidarity can be disaggregated into distinct but interrelated versions of solidarity that vary between collective or state and individual addressees. Most importantly, international solidarity between states is less welcome than solidarity towards vulnerable groups in other member states outside of a pandemic context as well.

If political discourse is one side of the coin, public support is its other side since both resonate with each other. Thus, the three articles discussed in this section address different but interrelated dimensions of the politics of solidarity accordingly: policies, political discourse and public support. Another crucial aspect most of the papers in this issue attend to is the relationship between public and third-sector solidarity, a relationship usually framed as being complementary. However, the strict distinction between state and civilsociety practices fails to do justice to the multifarious crisis responses. Mazzola and De Backer (2021, in this issue) argue that "what happened on the ground did not fit in a taxonomy of state (top-down) vs. civil society (bottom-up) solidarity. Instead, many important initiatives took place in an improvised, creative and hybrid fashion, sometimes beyond the original mission of the actors involved." Also, Kuhnt (2021) as well as Walliser and De Gasperi (2021) share this insight when they provide empirical examples of unconventional partnership models, examples that try to compensate for market as well as government failures. They paint a broader picture of the entanglement of and cooperation between the different spheres and complete our image of the private and non-profit sectors as a merely complementing and reacting force by conceiving of it as more of a creative and coproducing actor. 


\subsection{From crisis to disaster: Explaining the revival of solidarity}

So far, the activities the authors study in this special issue seem to suggest an augmented solidarity of a particular type. This leaves us with the question of how one can explain this leap in solidarity. In her theory paper, Ulrike Sasse-Zeltner approaches the pandemic from the perspective of disasters and proposes to consult existing insights from disaster research in order to better understand such an unprecedented revival of solidarity. After introducing the concepts of disaster and catastrophe, the paper revisits various approaches from disaster research to derive theoretical propositions about the current pandemic and provides a deeper understanding of the emergence of solidarity in disasters. The explanatory attempts that she cites draw on two classical solidarity approaches: Durkheim's macrosocial theory of mechanical and organic solidarity and socio-psychological explanations of intergroup behaviour (Tajfel \& Turner, 1986). They thus combine two different worlds of solidarity: solidarity as a macro phenomenon relying on common beliefs and interests and solidarity as a micro phenomenon based on group membership and the drawing of boundaries between in- and outgroups. In a final step, Sasse-Zeltner adapts Lars Clausen's macro-sociological model of disaster figurations to solidarity research. This model enables an interdisciplinary analysis of the changes in solidarity for different national societies and from a comparative perspective.

Compared to everyday practices, solidarity during disasters is more likely to have a spontaneous, temporary and improvised character. In contrast to crises, disasters affect the entire community, disrupt its daily functions and complicate or impede the work of local authorities and public facilities. It was not just the WHO and the EU that declared the state of international disaster in January 2020; states of emergency have also been declared at the state and regional levels (e.g., France, Spain; Bergamo, Bavaria). Given the regional variations in declaring a state of emergency, one cannot simply apply a standard model for disasters. This leads the author to argue that a detailed case study on the solidarity practices during COVID-19 requires the researcher to consider the specific conditions under which solidarity is exercised.

From a disaster- and macro-sociological perspective and drawing on the work of Wolf Dombrowsky, Sasse-Zeltner interprets COVID-19 solidarity from below as mechanical solidarity or a process of Vergemeinschaftung. Unlike organic solidarity that is based on the social division of labour (Durkheim, 1997 [1893]), this form reacts to the partial breakdown of the institutional order and public infrastructure and thus of the functional division of labour in society and seeks to accommodate extraordinary circumstances. Even more than crises, disasters open a window of opportunity because they temporally shift the boundaries within which solidarity is usually granted, that is, solidarity is either shifted from group A to group B or is expanded from group A to group B only. During the first wave of COVID19-hence for a specific but limited period of time-the new ingroup comprised all persons affected by the pandemic and the lockdown (and therefore practically everyone) but especially the at-risk groups, the 'key workers' and those particularly struck by the lockdown. This very first period of the pandemic, the author assumes, changed people's awareness of their vulnerability and exposure to infectious diseases and made diseaserelated solidarity practices more attractive since we lacked proper solutions and knowledge (such as medical treatment and vaccination). However, ingroup constructions of who is a proper victim have differentiated over time and vary in different social groups' perceptions. Here, the approach proposed by the author provides useful insights with respect to temporal analysis and allows one to formulate some assumptions on how practices of solidarity have shifted over time: "a phase of increasing solidarity is followed by a phase of bitter conflict, characterized by the search for scapegoats and the emergence of old factionalisms and widely manifested hostility" (Sasse-Zeltner, 2021, in this issue, see also Turner, 1967, 61). 
Sasse-Zeltner concludes that the long-term effects of the ongoing pandemic are likely to transform the numerous spontaneous forms of solidarity studied in this special issue and elsewhere into a period of de-solidarization, for instance, when conflict around the allocation of scarce resources erupts, a process we are partly witnessing right now with respect to the allocation of vaccines or when those economically affected by the lockdown begin to question measures such as wearing masks or social distancing. Now that a new period of pandemic-related solidarity is likely to start the insights into the first spontaneous bottom-up as well as top-down solidarity practices the pandemic has triggered provided in this issue are especially important.

\section{What remains?}

Insights from research on previous crises and studies comparing different crises suggest that each crisis creates its own version of solidarity (or de-solidarization) (Agustín \& Jørgensen, 2016; della Porta, 2018; Lahusen \& Grasso, 2018). Viewed together, the papers in this special issue provide examples of the manifold facets of solidarity and offer an early overview of how COVID-19 has altered the existing solidarity landscape in Europe since the first half of 2020 when the first wave reached most European states. They contribute to a broad understanding of solidarity as a continuum of practices that take place between the private and the public sphere, with individual volunteers (as well as civil-society organizations) and different public actors constituting the two poles of this continuum. Furthermore, this also adds to an understanding that may prove crucial in grasping the challenges of pandemic waves to come and the waning support or confidence in collective responses to the pandemic.

Quite a few of the commentaries that have been written during the last twelve months are full of optimistic forecasts in which solidarity features as one of the main acts. While supranational initiatives such as the European Health Union presented by the European Commission in November 2020 has raised hope that the EU will advance its social dimension (Guy, 2020), others see the welfare state as "back in" and "here to stay" (Sandher \& Kleider, 2020). Altogether, this might possibly result in a revival of the civic and "public sector after years of neoliberal folly" (Zielonka, 2020,3) in its local, national and European dimension (instead of re-nationalization - a buzzword that was used widely at the beginning of pandemic but gave way to more differentiated assessments). In particular, as the pandemic has thrown new light on the long-term effects of neoliberal social policies and has linked different crises with each other (Giraud et al., 2021; Walliser \& De Gasperi, 2021 and Mazzola \& De Backer, 2021, all in this issue), this gives reason to hope that COVID-19 will help to end austerity and herald a new era for the welfare state and public policies in general. It also raises the question to which extent national boundaries might lose importance and the European level might assume new responsibilities.

Another question is whether civil-society organizations will be winners of the crisis. With regard to the role of civil society, grassroots initiatives and private activities in providing support, the empirical studies point to the importance of existing networks and an extraordinary dynamic of civic solidarity. Yet, the creation (or support) of a sustainable infrastructure of non-profits that is able to react in such a creative and flexible way also in future crises is, at least partly, in the hands of the public sector.

Dubet $(2020,4-5)$ sees a "return of society" as both the virus and the related interventions - often highly improvised-have made us aware not only of the social division of labour, the functioning of organizations and the way we depend on each other but also of how this intersects with personal autonomy as well as fundamental and social rights. Of course, the burden sharing within families, municipalities, national societies and beyond existed during the era of the paternalistic state and the night-watchman state, too, and 
yet COVID-19 has rendered these interdependencies particularly visible. With this in mind, Zielonka assumes:

"The shock of 2020 may leave us shattered and divided, but it may also mobilize us to rebuild and enlarge the public sphere, to offer citizens meaningful forms of participation in public affairs, to bring markets under democratic scrutiny, and perhaps even to create a caring society able to respect labor (including migrant labor), the environment, and citizens' health." (Zielonka, 2020, 1)

However, the coronavirus crisis would not be a crisis if there were only winners. First and foremost, the pandemic has been characterized by many short-lived and isolated interventions, many of which will leave the scene as fast as they entered it. What is more, the common ground (common interests, common ideas, common values or beliefs etc.) the above-mentioned developments rely on will have to inform the welfare state and the civil society likewise. However, COVID-19 may not necessarily offer much common ground as the pandemic has affected young and old, rich and poor, those with and without children quite differently. For the sake of clarity, it could therefore be useful to distinguish between different coronavirus-induced crises (e.g., exacerbated social inequalities, a supply crisis, the crisis of public health, a lockdown-induced economic crisis and an anti-scientific populism fuelled by anti-lockdown protests) instead of speaking of one single crisis. Last but not least, given the pandemic's long-term nature, one can only guess what kind of challenges post-pandemic societies will have to face. For instance, an issue such as remote work, which is widely considered to be a major opportunity for the world of employment, comes at the price of new risks-especially from a macro-sociological viewpoint, which assumes everyday encounters and practices of exchange between different social groups to be a crucial condition for solidarity in modern societies.

\section{References}

Agustín, O.G. \& Jørgensen, M.B. (2016). Solidarity without borders: Gramscian perspectives on migration and civil society alliances. In O.G. Agustín \& M.B. Jørgensen (Eds.), Solidarity without Borders: Gramscian Perspectives on Migration and Civil Society Alliances (322). London: Pluto Press.

Börner, S. (2013). Belonging, Solidarity and Expansion in Social Policy. Basingstoke: Palgrave Macmillan.

della Porta, D. (2018). Contentious Moves: Mobilising for Refugees' Rights. In D. della Porta (Ed.), Solidarity Mobilizations in the 'Refugee Crisis'. Contentious Moves (1-38). Cham: Palgrave.

Dubet, F. (2021). The return of society. European Journal of Social Theory, 24(1), 3-21.

Durkheim, E. (1997[1893]). The Division of Labour in Society. New York: Free Press.

Fiedlschuster, M. \& Reichle, L. R. (2021). Global pandemic, local solidarity: Six civic initiatives from Leipzig, Germany. Culture, Practice \& Europeanization, 6(1), 39-54.

Gelissen, J. (2000). Popular support for institutionalised solidarity: a comparison between European welfare states. International Journal of Social Welfare, 9(4), 285-300. 
Gerhards, J., Lengfeld, H., Ignácz, Z.S., Kley, F.K. \& Priem, M. (2019). European Solidarity in Times of Crisis. London and New York: Routledge.

Gerhards, J. (2020). Europäische Solidarität in der Corona-Krise. Berliner Studien zur Soziologie Europas Nr. 41, April 2020, Berlin.

Giraud, O., Tietze, N., Toffanin, T. \& Noûs, C. (2021). The Scalar Arrangements of Three European Public Health Systems Facing the COVID-19 Pandemic: Comparing France, Germany, and Italy. Culture, Practice \& Europeanization, 6(1), 89-111.

Gustafsson, M. \& McCurdy, C. (2020). Risky business: Economic impacts of the coronavirus crisis on different groups of workers. Resolution Foundation, London.

Guy, M. (2020). Towards a European Health Union: What Role for Member States? European Journal of Risk Regulation, 11(4), 757-765.

Koos, S. (2019). Crises and the reconfiguration of solidarities in Europe - origins, scope, variations. European Societies, 21(5), 629-648.

Kuhnt, J. (2021). The network function of civil society organizations in times of the COVID19 pandemic - or how engagement as a practice of solidarity becomes market-relevant. Culture, Practice \& Europeanization, 6(1), 70-88.

Lahusen, C. \& Grasso, M.T. (2018). Solidarity in Europe: A comparative assessment and discussion. In C. Lahusen \& M.T. Grasse (Eds.), Solidarity in Europe. Citizens' Responses in Times of Crisis (253-281). Cham: Palgrave.

Mazzola, A. \& De Backer, M. (2021). Solidarity with vulnerable migrants during and beyond the state of crisis. Culture, Practice \& Europeanization, 6(1), 55-69.

Polyakova, A. \& Fligstein, N. (2016). Is European integration causing Europe to become more nationalist? Evidence from the 2007-9 financial crisis, Journal of European Public Policy, 23(1), 60-83.

Prainsack, B. (2020). Solidarity in Times of Pandemics. Democratic Theory, 7(2), 124-133.

Rachman, G. (2020). Nationalism is a side effect of coronavirus. The pushback against globalisation will come from protectionists, national-security hawks and greens. Financial Times, March 23, 2020. Retrieved from: https://www.ft.com/content/644fd920-6cea11ea-9bca-bf503995cd6f. Accessed 24 March 2021.

Rakopoulos, T. (2014). Resonance of Solidarity: Meanings of a Local Concept in Anti-austerity Greece. Journal of Modern Greek Studies, 32(2), 313-337.

Reese, G. \& Lauenstein, O. (2014). The Eurozone Crisis: Psychological Mechanisms Undermining and Supporting European Solidarity. Social Sciences, 3(1), 160-171.

Salamon, L. (1995). Partners in Public Service. Baltimore: Johns Hopkins University Press.

Sandher, J. \& Kleider, H. (2020): Coronavirus has brought the welfare state back, and it might be here to stay. The Conversation, Juni 24 2020. Retrieved from: 
https://theconversation.com/coronavirus-has-brought-the-welfare-state-back-and-itmight-be-here-to-stay-138564. Accessed March 242021.

Sasse-Zeltner, U. (2021). The revival of solidarity in disasters - a theoretical approach. Culture, Practice \& Europeanization, 6(1), 158-178.

Schiller, C. \& Hellmann, T. (2021). Major differences in the conditions for successful COVID19 crisis management. Bertelsmann Stiftung.

Tajfel, H. \& Turner, J. (1986). The Social Identity Theory of Intergroup Behaviour in S. Worchel \& W. G. Austin (Eds.), Psychology of Intergroup Relations (7-24). Chicago: Nelson Hall.

Turner, R. (1967). Types of solidarity in the reconstituting of groups. The Pacific Sociological Review, 10(2), 60-68.

Wallaschek, S. (2020). The Discursive Construction of Solidarity: Analysing Public Claims in Europe's Migration Crisis. Political Studies, 68(1), 74-92.

Walliser, A. \& De Gasperi, F. (2021). Who cares for what? Care networks and new urban activisms in Madrid: Restating solidarity. Culture, Practice \& Europeanization, 6(1), 15-38.

WHO (2020). Pandemic preparedness. Retrieved from: https://www.euro.who.int/ en/health-topics/communicable-diseases/influenza/pandemic-influenza/pandemic-preparedness. Accessed 11 March 2021.

Young, D. R. (2000). Alternative models of government-nonprofit sector relations: Theoretical and international perspectives. Nonprofit and Voluntary Sector Quarterly, 29(1), 149-172.

Zielonka, J. (2020). The Politics of Pandemics. Global Perspectives, 1(1), 1-6. 